\title{
SPATIAL AND TEMPORAL EVOLUTION AND COORDINATION ANALYSIS OF POPULATION, SPACE AND ECONOMY IN CENTRAL PLAIN CITY CLUSTER OF CHINA
}

\author{
ZHOU, P. C. ${ }^{1}-$ YANG, Y.F. $^{2 *}$ \\ ${ }^{I}$ School of Surveying and Urban Spatial Information, Henan University of Urban Construction, \\ Pingdingshan 467036, China \\ (phone: +86-158-9098-3715) \\ ${ }^{2}$ College of Environment and Planning, Henan University, Kaifeng 475004, China \\ *Corresponding author \\ e-mail: yyfnp@henu.edu.cn; phone: +86-182-3787-8989 \\ (Received $1^{\text {st }}$ Mar 2019; accepted $21^{\text {st }}$ May 2019)
}

\begin{abstract}
Taking the Central Plain City Cluster of China as the research object, and using the center-ofgravity coupling model, unbalance index, and coordination measure model, this paper analyzed spatial and temporal evolution characteristics of coordination between urban population, built-up area, and economy in 2008-2016, and predicted their overall development trend in combination with the Logistic model. It obtained following results: (i) The growth rate of urban economy is faster than that of urban population and built-up area, and the stage characteristics and spatial differences of their evolution are significant. (ii) On the whole, the shift direction of population is opposite to that of built-up area and economic gravity, the coordination between population and built-up area and economy gradually declines, while the shift direction of built-up area is the same as that of the economic center-of-gravity, and the coordination between built-up area and economy is gradually strengthened. The unbalance index of population, built-up area and economy is on the rise, while unbalance index of population and built-up area remains stable. (iii) The spatial difference characteristics of the coordination between them are significant. Specifically, the coordination is poor between population and built-up area and economy, while the coordination is good between built-up area and economy. (iv) According to the prediction, the overall size of urban population, built-up area and economy of the Central Plain City Cluster will be 29.4 million, $4,355 \mathrm{~km}^{2}$, and 4.549 billion yuan in 2026 , and such prediction is very believable.
\end{abstract}

Keywords: urbanization, center of gravity coordination model, unbalanced index, coupling, coordination degree, logistic prediction

\section{Introduction}

As the world's fastest-growing economy, since the reform and opening up, China has been accelerating in the urbanization process, and both the speed and scale of its urbanization are unprecedented (Chan and Yao, 1999; Niu et al., 2014; Feng et al., 2014). According to the estimation by the Development Research Center of the State Council of China, the peak rate of urbanization in China is $70 \%-75 \%$, and it will get close to $67 \%$ by 2030 . In other words, in a long period of time in the future, China's urbanization process will still maintain a high development speed, and the city scale will be further expanded. Therefore, how to maintain coordinated and orderly development will become particularly important in the process of high-speed urbanization.

As an important characterization of the urbanization process, population, built-up area and economy have close connection and interaction in the scale, speed, structure, quality and benefits of urbanization (Shi, 2015; Wang et al., 2014). Urbanization should 
be a complex process of interaction and coordinated development of the threedimensional integrated system of "population - built-up area - economy". However, in the process of rapid urbanization development of small and medium-sized cities in China, there appear various problems such as excessive accumulation of population, low intensive use of urban land, lopsided industrial structure, and extensive economic development, leading to the imbalance between population, built-up area, and economic system (Di et al., 2016; Lin, 2007, 2006; Friedmann, 2010). Such imbalance has greatly restricted further development of China's urbanization (Fan et al., 2014; Tang, 2013). In this situation, the study on coordinated development of population, built-up area, and economy has great realistic significance for healthy and sustainable development of urbanization.

Some studies have shown that urbanization is the spatial and temporal evolution of regional socio-economic processes, mainly reflected in population, economy, space and society (Ameen et al., 2015; Liu et al., 2014). In the process of urbanization, any subsystem in the population, the built-up area, and economy gets ahead or lags behind the development of other subsystems will lead to an imbalance in the overall development of urban society (Chen, 2008; Liu and Yamauchi, 2013; Holden and Otsuka, 2014). With reference to the above studies, we believe that the healthy and sustainable development of the economy, population, and built-up area is the coordinated development of "population - built-up area - economy". Some scholars such as Henderson and Cohen demonstrated the importance of the coordination of urban population and economy to the healthy development of urbanization; they pointed out that population urbanization is the core and economic urbanization is the driving force, and the quantitative relationship between population urbanization and economic urbanization determines the basic trend and economic benefits of urbanization, while the lag of the development of built-up areas will lead to various problems of resources and environment (Henderson, 2002; Cohen, 2008; Ravallion et al., 2007; Murakami et al., 2005; Ameen et al., 2015). Based on the relatively independent and non-inclusive variables of urban built-up area and urban population, Yang Yanzhao et al. built the relationship model between urban built-up area expansion and population growth, and evaluated the coordination between urban built-up area expansion and population growth (Yang et al., 2013; Zhou et al., 2016). They found that the rapid expansion of built-up areas, as the main type of urban development, has weakened the coordination between built-up area expansion and population growth. From the perspectives of regional structure, construction land structure, and urban scale structure, Wang Chengxin et al. analyzed the relationship between urban population growth and built-up area expansion in China, and found that there is a significant regional and structural difference between urban population growth and built-up area expansion (Wang et al., 2016).

Some existing studies also explored methods of urban measurement. Using Logistic regression, Zhang Leqin et al. measured the relationship between urban built-up area expansion and economic development (Zhang et al., 2014). Using exploratory spatial data analysis and coupling coordination model, He Sanwei et al. analyzed the coupling coordination type and spatial distribution of population, land and economic urbanization in Beijing-Tianjin-Hebei region, and found that most cities have difficulties in achieving a good level of coordinated development (He and Shao, 2018). Different scholars have different judgment criteria for coordination, but the research results have indicated that there are obvious spatial differences in the coordination relationship 
between population, built-up area and economic urbanization subsystems, and the uncoordinated phenomenon is very prominent. Through the above findings, we have a deeper understanding of the changes in the relationship between the development of urbanization subsystems and the spatial distribution of the coupling coordination state. However, there are still some shortcomings in the existing studies. (1) There are few studies on urban scale measurement, and most studies focus on the expansion model, model and dynamic mechanism (Xu et al., 2007; Liu and Yang, 2011). Some scholars discussed from the perspective of the population and built-up area (Li et al., 2011; Liu and Wang, 2011). There is no prediction about the urban population, the built-up area, and the future trend of the economy, so it is impossible to formulate preventive policies for relevant issues. (2) In terms of the research area, many studies focus on China's coastal areas (Li et al., 2018; You et al., 2017; Wang et al., 2018), but few studies care about the inland urban city cluster in the process of rapid urbanization, and such areas are exactly the areas with prominent problem in the coordination between the urban population, built-up area, and economy. This is mainly because there is still no clear definition of the theoretical connotation of urbanization coordination in the academic circle (The concept of coordination comes from the "coordinated development of urban and rural areas" proposed by the central government. As a part of the harmonious society theory, it describes the state of balanced development between urban and rural areas.). Besides, there is no criterion for measurement indicator system. In addition, the coordinated development is a description of dynamic interactions, and the specific evaluation conclusions need to be combined with local situations, so it is difficult to unify the weight of indicators. With reference to the existing studies, we believe that the population - built-up area - economic urbanization subsystems have the same effect on the overall coordinated development. Therefore, we used the proportion of the population, build-up area, and economic growth rate of each city to that of the Central Plain City Cluster to characterize the contribution share of each subsystem. If the contribution share of each subsystem is consistent, it will be deemed to be the theoretical optimal state. The Central Plain City Cluster is a central inland region of China with rapid urbanization. Problems exposed in the process of its urbanization development are representative. Thus, study on the coordination of "population - builtup area - economy" of this region is helpful for deeply understanding the quality and rules of its urbanization development, and has great realistic significance for healthy and sustainable development of the regional urbanization. On the basis of studies both at home and abroad, considering the relationship between population size, GDP and built-up area of the Central Plain City Cluster, we established a mathematical model to measure the coordination between urban population, built-up area and GDP of the Central Plain City Cluster. Besides, we introduced the center of gravity model and the imbalance index to study the spatial and temporal evolution characteristics and coordination relationship of the population, built-up areas and economy of 30 provincial cities in the Central Plain City Cluster in 2008-2016. Finally, using the Logistic model, we predicted the future development trend of urban population and built-up area in the Central Plain City Cluster of China, in the hope of providing certain references for properly adjusting the relationship between urban population, land use, and economic development, and promoting the coordinated development of urbanization. 


\section{Overview of the study area}

The Central Plain City Cluster is located in the central eastern of China (Fig. 1). As an intersection of "two horizontal lines and three vertical lines" urbanization strategy, it is a core growth pole for undertaking the industrial transfer of foreign countries and China's eastern regions, resource output of western regions, and driving the development of central and western regions of China. This region has excellent natural endowments, the terrain is mainly plain, with hills and mountains; human resources are abundant, the industrial system is complete, and the advantages of industrial clusters are obvious and the innovation ability is continuously enhanced; the transportation location is superior, the three-dimensional transportation network is gradually improved, and alldirection accessible comprehensive transportation hub based on the railway transportation is gradually forming; urban system is complete, and it is gradually forming the coordinated development pattern of large, medium and small cities and small towns. The Development Plan for Central Plain City Cluster, issued by the State Council of China on December 28, 2016, clearly defined the scope of this region, and divided this region into 6 zones according to the city type and regional industrial structure: Zhengzhou Metropolitan Zone, Core Development Zone, Northern Transregional Coordinated Development Demonstration Zone, Eastern Industrial Transfer Demonstration Zone, Western Transformation and Innovation Development Demonstration Zone, and Southern High Efficiency Ecological Economic Demonstration Zone. By the end of 2016, the area of Central Plain City Cluster was $287,000 \mathrm{~km}^{2}$, the total population was 162.1082 million, the GDP was $6,034.372$ billion yuan with the per capita GDP of 37,200 yuan, making this region become the fourth growth pole of Chinese economy, following the Yangtze River Delta, the Pearl River Delta, and Beijing-Tianjin-Hebei economic circle. Therefore, how to realize the spatial optimization and coordinated development of population, built-up area and economy is an important issue confronted by the Central Plain City Cluster.

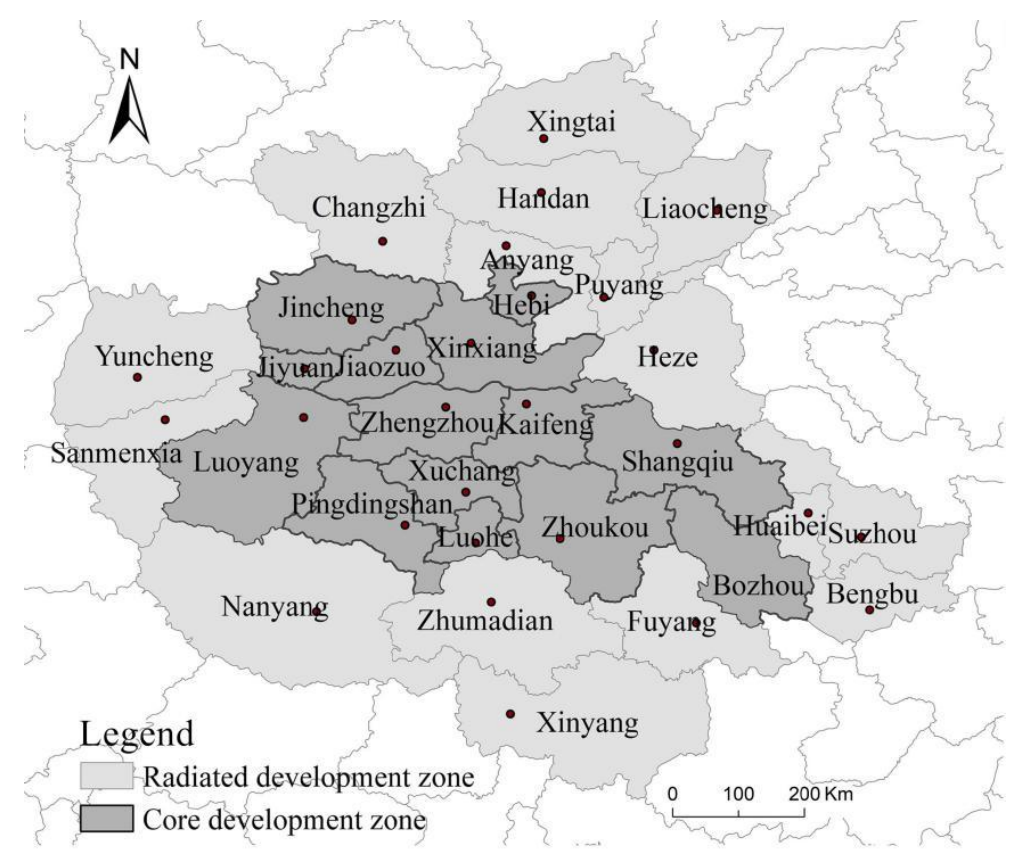

Figure 1. Map for Central Plain City Cluster 


\section{Study method and data source}

\section{Study method}

\section{Center of gravity coordination model}

In this study, we adopted the center-of-gravity model and center-of-gravity spatial coupling trend to reflect the overall coupling trend of the growth of population, built-up area, and economy of 30 cities in Central Plain City Cluster. The center-of-gravity model is as follows (Zhou et al., 2016):

$$
G_{I}(x, y)=\frac{\sum_{j}^{n}\left(Q\left(x_{j}, y_{j}\right)\right)}{\sum_{j}^{n} I_{j}}
$$

where $G_{I}$ denotes the center of gravity of urban population, built-up area or economy; $I=1,2$, and 3 denotes population, built-up area, and economy, respectively; $n$ denotes the number of study areas; $I_{j}$ denotes the population, built-up area or economy of the $j$-th city; $x_{j}$ and $y_{j}$ denote the longitude and latitude of the $j$-th city.

Using the overlapping of spatial distribution and the consistency in track of centerof-gravity changes, we observed the spatial coupling trend in center of gravity of 30 cities in Central Plain City Cluster. The overlapping of spatial distribution can be calculated with the following formula (Zhou et al., 2016):

$$
S=\sqrt{\left(\Delta x_{G}\right)^{2}+\left(\Delta y_{G}\right)^{2}}
$$

where $S$ denotes the distance of center of gravity between urban population and built-up area, between population and economy, and between built-up area and economy; $x_{G}$ and $y_{G}$ denote the longitude and latitude of the center of gravity; closer distance means higher overlapping.

The consistency in track of center-of-gravity changes can be calculated with the following formula (Zhou et al., 2016):

$$
C=\cos \theta=\frac{\left(\Delta x_{A} \Delta x_{B}\right)+\left(\Delta y_{A} \Delta y_{B}\right)}{\sqrt{\left(\Delta x_{A}^{2}+\Delta y_{A}^{2}\right)+\left(\Delta x_{B}^{2}+\Delta y_{B}^{2}\right)}}
$$

where $\cos \theta$ denotes the cosine value of the vector angle $\theta$ of displacement of the center of gravity of urban population and built-up area, population and economy, and built-up area and economy in this time point relative to that in last time point, and it is in the range of $[-1,1]$, and higher value means greater consistency of variation; $\Delta x$ and $\Delta y$ denote variation of the longitude and latitude of the center of gravity of this time point relative to the last time point. In this paper, Excel 2007 software is used to process data and charts.

\section{Unbalance index}

In order to study the distribution of urban population, built-up area and economy, with reference to previous studies, we constructed an unbalance index characterizing the 
overall balance of urban population, built-up area, and economy. The unbalance index can be calculated with the following formula:

$$
U=\sqrt{\frac{\sum_{i=1}^{n}\left[\frac{\sqrt{2}}{2}\left(X_{i}-Y_{i}\right)\right]^{2}}{n}}
$$

where $U$ denotes the unbalance index, $n$ denotes the number of study unit, $X_{i}$ and $Y_{i}$ denote the proportion of population and built-up area, population and economy, and built-up area and economy to the total amount. The unbalance index reflects the coupling relationship between population and built-up area, population and economy, and built-up area and economy. The smaller the $U$ value, the more balanced the distribution. In this paper, Excel 2007 software is used to process data and charts.

\section{Spatial coordination measure model}

The coordination degree is an indicator reflecting the degree of internal dependence of different factors. It can be used to judge the degree of interdependence and close relationship between urban population, built-up area and economy. Its function is:

$$
C=\frac{X+Y}{\sqrt{X^{2}+Y^{2}}}
$$

where $C$ is the coordination degree, representing the coordination degree between population and built-up area, between population and economy, and between built-up area and economy, with the value in the range of $[-1.4142,1.4142]$, the higher the $C$ value, the better the coordination; $X$ and $Y$ denote the proportion of urban population, built-up area, and growth rate of economic scale to the total population, total built-up area, and growth rate of total economic scale, respectively. According to the proportional relationship between population, built-up area and economy, we divided the coordination degree into four types: $C \geq 1.3868$ means coordinated (difference below 0.5 times), $1.3868>C \geq 1.3416$ means relatively coordinated (difference $0.5-1$ times), $1.3416>C \geq 1.2649$ means relatively uncoordinated (difference 1-2 times), and $C<1.2649$ means uncoordinated (difference above 2 times). In this paper, Excel 2007 software is used to process data and ArcGIS 10 software is used to visualize the calculation results.

\section{Logistic prediction model}

Predicting the trend of changes in the urban population, built-up area, and economic scale is favorable for the control of urban size and making the development plan. In view of this, using Logistic model, we predicted the development trend of urban population, built-up area and economy, to provide theoretical recommendations for the promotion of urbanization construction in a scientific and proper manner. The Logistic growth model is as follows: 


$$
S_{t}=\frac{S_{\max }}{1+\left(S_{\max } / S_{0}-1\right) e^{-k_{s} t}}
$$

where $S_{\max }$ denotes the maximum of simulated object, and $k_{s}$ denotes the initial growth rate of simulated object. In this paper, Excel 2007 software is used to process data and charts.

\section{Data source}

The basic data involved in this study included population, built-up area and economy. For the population indicator, we took the resident population of the urban area; for the built-up area indicator, we used the area of the built-up area; for the economic indicator, we used the urban GDP. All data were selected from China Urban Construction Statistical Yearbook (2008-2016).

\section{Result analysis}

\section{Characteristics of spatial and temporal evolution}

\section{Characteristics of temporal evolution}

In 2008-2016, the urban population, built-up area, and economic scale of Central Plain City Cluster showed a linear growth trend. Specifically, the population increased from 20.68 million to 24.65 million, with an average annual growth rate of $2.22 \%$; the built-up area scale increased from $2,073 \mathrm{~km}^{2}$ to $3,031 \mathrm{~km}^{2}$, with an average annual growth rate of $4.87 \%$; the economic scale increased from 660.5 billion yuan to $1,775.4$ billion yuan, with an average annual growth rate of $13.16 \%$. From Figure 2 it can be seen that the growth rate of urban population, built-up area and economy of Central Plain City Cluster showed a fluctuating trend.

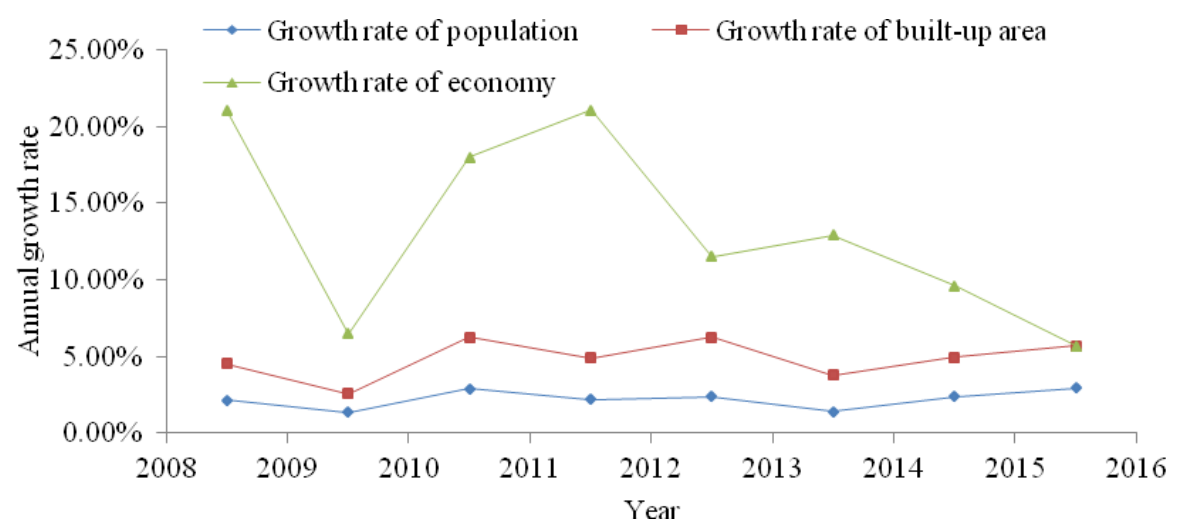

Figure 2. Growth rate of urban population, built-up area, and economy of Central Plain City Cluster in 2008-2016

Specifically, the variation trend of growth rate of built-up area expansion and population was basically consistent, while the growth rate of economy showed a significant decline. In 2008-2010, due to the impact of the international financial crisis, urban economic growth rate declined rapidly, the urban construction rate slowed down, 
the employment opportunities decreased, leading to a decline in the growth rate of population and built-up area. In 2010-2014, with the support of the state policy of vigorously promoting urban infrastructure construction, a new round of urban development and industrial park construction drove the rapid economic development, which consequently led to the expansion of urban built-up area and the population agglomeration. Although external capital stimulus has promoted economic development in a short term, urban development lacks internal motivation, so that the growth rate of urban population, built-up area and economy fluctuated. In 2014-2016, the national economic stimulus policy came to an end, and the economic growth rate declined. With the gradual improvement of urban functions, urban population and built-up area entered a steady growth stage. On the whole, the variation in growth rate of urban population, built-up area and economy was not in the same proportion, the economic growth rate was the highest and the population growth rate was the lowest.

\section{Characteristics of spatial evolution}

Figure 3 depicted the spatial distribution of growth rate of urban population, built-up area, and economy of Central Plain City Cluster.
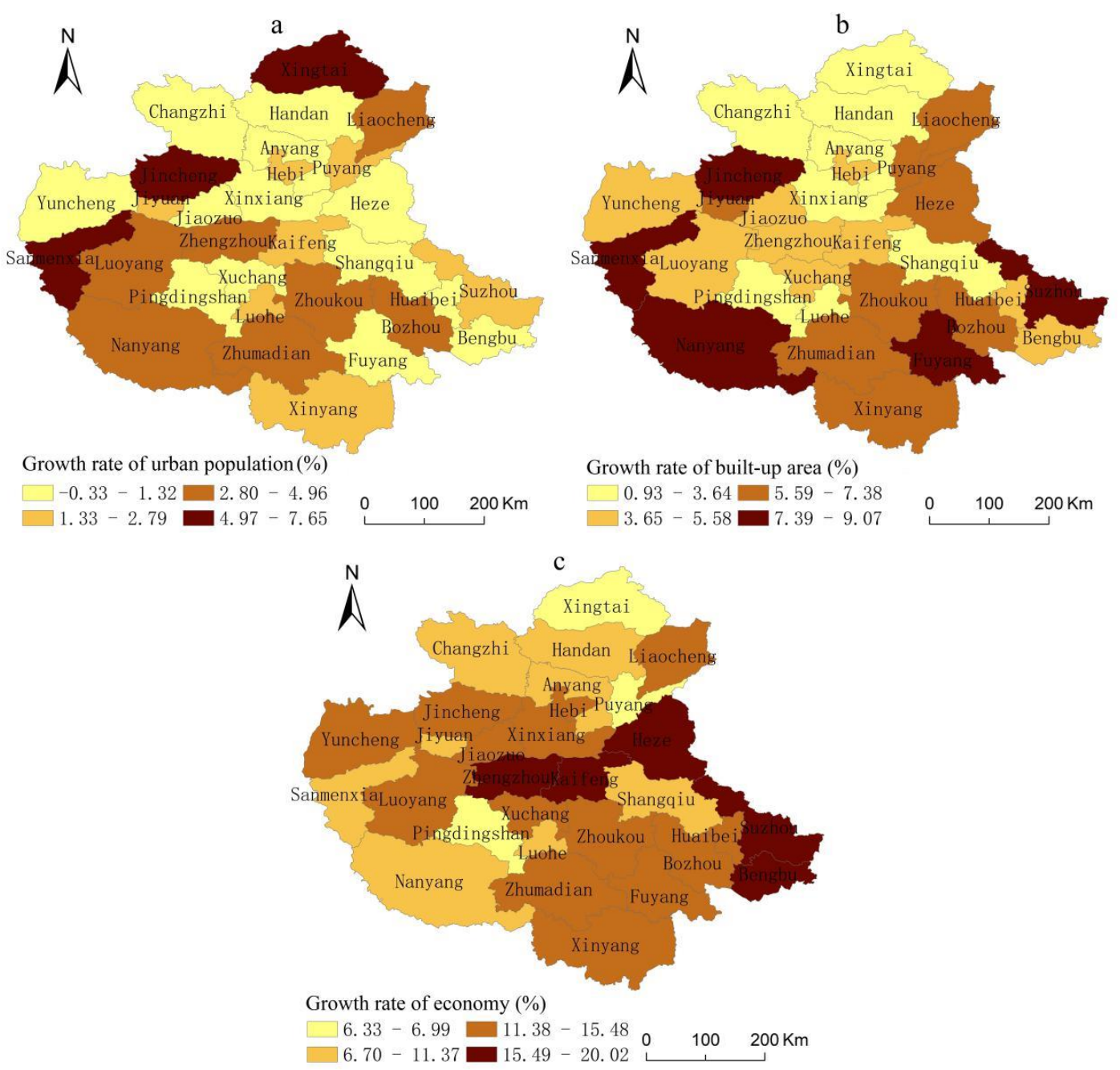

Figure 3. Spatial distribution of growth rate of urban population (a), built-up area (b), and economy (c) of Central Plain City Cluster in 2008-2016 
It showed significant spatial difference in growth rate of population, built-up area, and economy. In the study period, the growth rate of urban population was mainly concentrated in the range of $1.33-2.79 \%$ and $2.80 \%-4.96 \%$, accounting for $43.33 \%$ and $23.33 \%$ of the total number of cities respectively; the growth rate of population of different cities was relatively close to each other. In terms of built-up area rate, the number of cities in different grades is basically the same. The growth rate of built-up area was mainly concentrated in the range of $3.65 \%-5.58 \%$, and both were in the Midwest of the city cluster, accounting for $30 \%$ of the total number of cities. In general, the growth rate of built-up area is faster than that of urban population. Driven by the tide of urbanization, land finance has become an essential means or urban development. The growth rate of urban economy was mainly concentrated in the range of $12.27 \%$ $16.22 \%$, accounting for $50 \%$ of the total number of cities. The cities with faster economic growth were concentrated in the central and western parts of the Central Plain City Cluster, mainly because, except Zhengzhou Metropolitan Zone, the Eastern Industrial Transfer Demonstration Zone, Western Transformation and Innovation Development Demonstration Zone, and Southern High Efficiency Ecological Economic Demonstration Zone realized collaborative development, forming a multi-regional development pattern.

\section{Analysis of coordination evolution}

\section{Overall coordination trend}

(1) Coordination trend of the center of gravity

According to Equation 1, the track of changes in urban population, built-up area, and economic center of gravity is calculated (Fig. 4). From Figure 4, it can be seen that the center of gravity of urban population, built-up area, and economy of Central Plain City Cluster was located in the northwest of the geometric center of gravity.

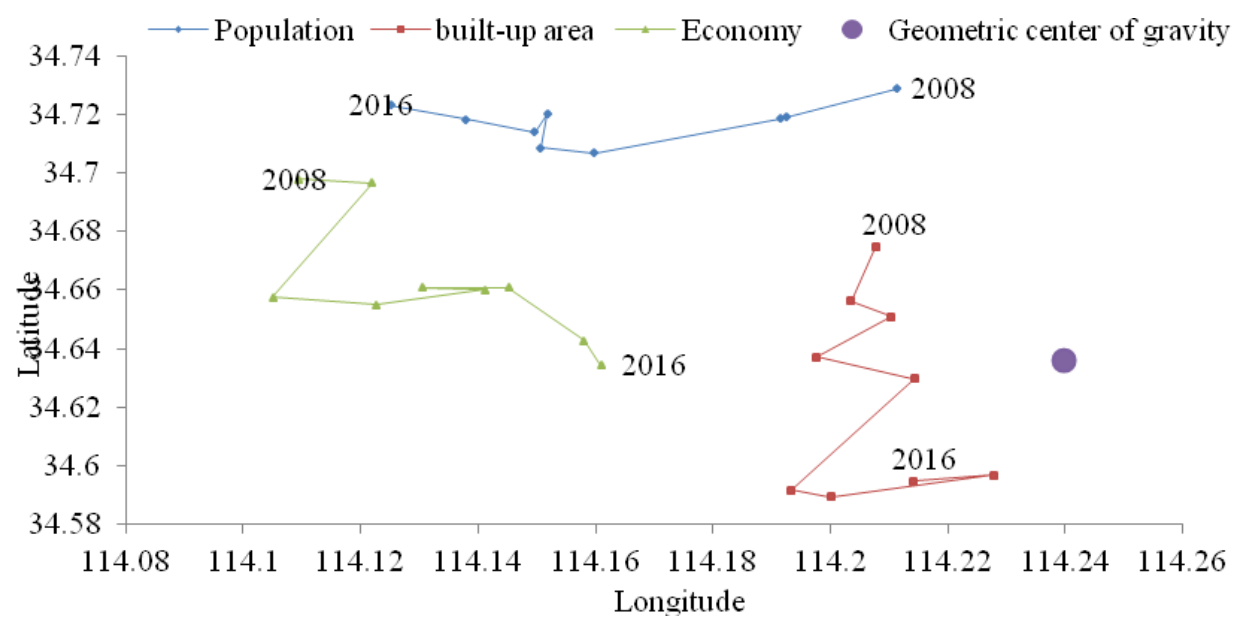

Figure 4. Moving tracks of center of gravity of urban population, built-up area, and economy of Central Plain City Cluster in 2008-2016

In 2008-2016, the center of gravity of urban population moved about $6.7 \mathrm{~km}$ to the west, with annual average moving distance of $1.33 \mathrm{~km}$; the center of gravity of urban population moved about $8.37 \mathrm{~km}$ to the south, with annual average moving distance of 
$1.98 \mathrm{~km}$; the center of gravity of urban economy moved about $9.16 \mathrm{~km}$ to the southeast, with annual average moving distance of $1.85 \mathrm{~km}$. On the whole, the moving distance of three centers of gravity was small, indicating that the distribution of population, built-up area, and economy of cities of Central Plain City Cluster was basically reasonable. Combined with Figure 3, the movement direction and growth rate distribution of the center of gravity were basically consistent in the urban population, built-up area, and economy; the growth of built-up area was mainly concentrated in the regions of south of Yellow River, and the center of gravity moved to the south, close to the geometric center of gravity; the center of gravity of population generally moved to the west due to influence of southwestern cities with faster population growth including Nanyang, Luoyang, Sanmenxia, and Zhengzhou; the center of gravity generally moved to the southeast due to the influence of cities with faster economic growth rate of central and southeastern cities.

According to Equations 2 and 3, the spatial overlapping and variation consistency in the center of gravity of urban population, built-up area and economy is calculated (Fig. 5).
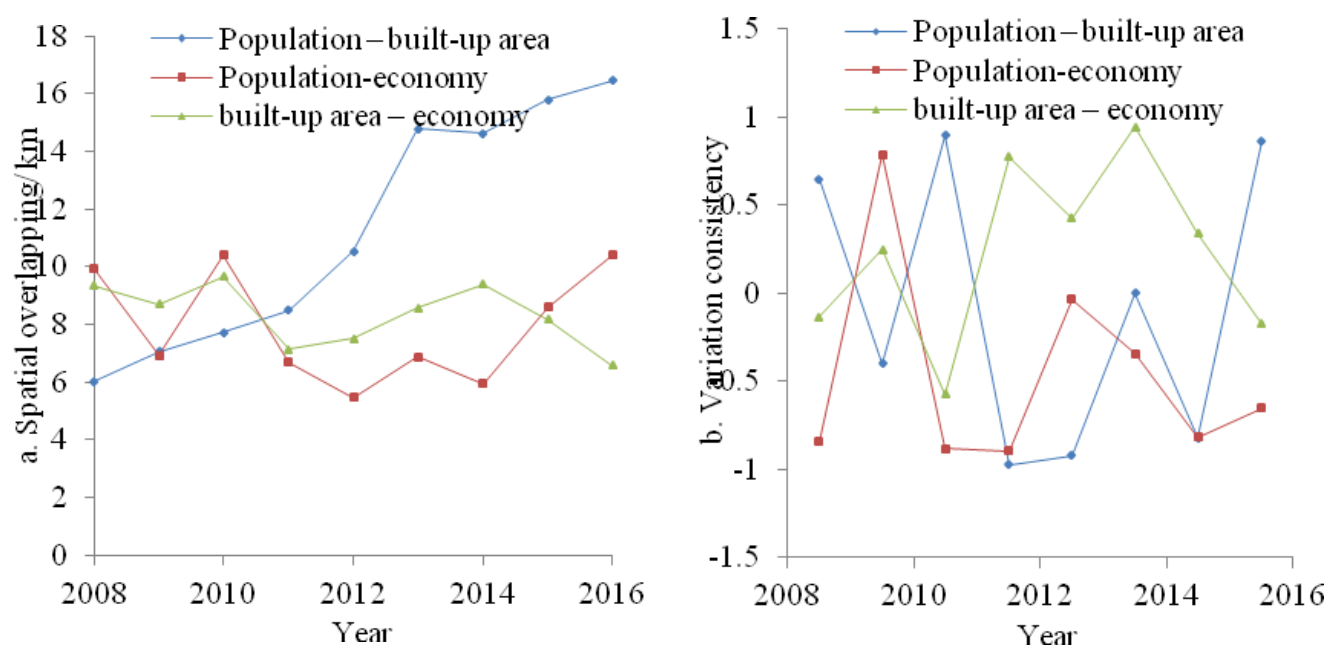

Figure 5. Spatial overlapping (a) and variation consistency (b) of center of gravity of urban population and built-up area in Henan Province

From Figure 5, it can be seen that: (i) The center-of-gravity distance between population and built-up area was generally on the rise, increasing from $6 \mathrm{~km}$ in 2008 to $16.5 \mathrm{~km}$ in 2016 , with the average value of $10.9 \mathrm{~km}$; the center-of-gravity overlapping was getting worse, and the coordination was declining; the variation consistency of the center of gravity between population and built-up area showed alternate changes of "the same direction - opposite direction", the variation consistency index was generally 0.12 , indicating that the center of gravity of population and built-up area moved in the opposite direction and the distance between the centers of gravity was constantly increasing. (ii) The center-of-gravity distance between population and economy showed a general trend of "decline - rise", increasing from $9.9 \mathrm{~km}$ in 2008 to $10.4 \mathrm{~km}$ in 2016 , with the average value of $8.1 \mathrm{~km}$; the center-of-gravity overlapping showed a small fluctuation; the variation consistency index of the center of gravity between population and economy was negative $(-2.69)$, indicating that the centers of gravity moved in the 
opposite direction, and the distance between the centers of gravity first increased then decreased, the coordination was poor. (iii) The center-of-gravity distance between builtup area and economy showed a declining trend, from $9.3 \mathrm{~km}$ in 2008 to $6.6 \mathrm{~km}$ in 2016 , with the average value of $8.4 \mathrm{~km}$; the center-of-gravity overlapping declined; the variation consistency of the center of gravity between built-up area and economy showed alternate changes of "the same direction - opposite direction", the variation consistency index was generally 2.32, indicating that the centers of gravity generally moved in the same direction, and the coordination gradually became greater.

(2) Evolution of unbalance situation

According to Equation 4, we calculated the unbalance index of population and builtup area, population and economy, and built-up area and economy of Central Plain City Cluster. The calculation results were shown in Figure 6.

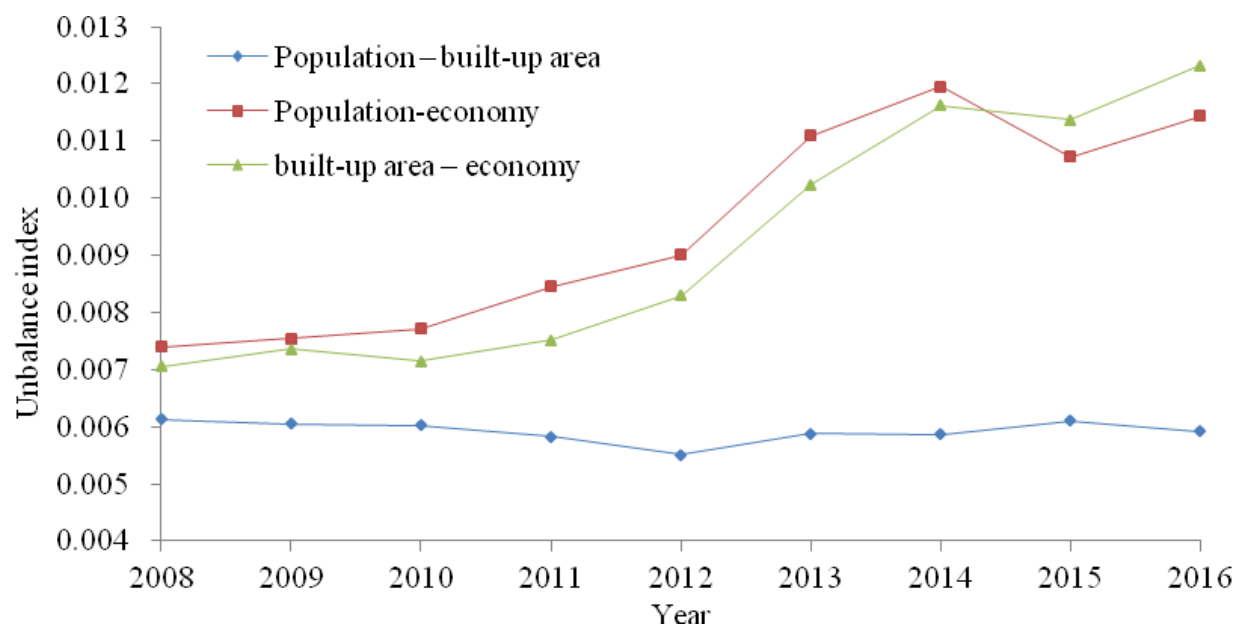

Figure 6. Unbalance index of population, built-up area, and economy of Central Plain City Cluster

Generally, the urban population-economy, and built-up area - economy unbalance index showed a fluctuation trend of "rise - decline - rise", and the variation trend of both was basically consistent, while the population - built-up area unbalance index was basically stable, showing a trend of "slow decline - slow rise". (i) In the study period, the population - built-up area unbalance index remained basically the same, with an average of 0.0059 , indicating that the population and built-up area elements realized a balanced development in space. (ii) On the whole, the population-economy unbalance index rose from 0.0074 to 0.0114 , and the built-up area - economy unbalance index rose from 0.0071 to 0.0123 . Main reason was as follows: when carrying out the transfer of eastern industries, central core cities did not realize the corresponding agglomeration of population, so that the unbalance appeared between population, built-up area, and economy in space, till the urban population agglomeration effect became gradually stronger in the late period, then the spatial distribution balance of population and economic elements got gradually strengthened. For small and medium-sized cities, because built-up area expansion rate was much higher than the economic growth rate, the spatial distribution of built-up area and economic elements became out of balance. 


\section{Trend of spatial coordination}

According to Equation 5, we calculated the coordination $(C)$ between population and built-up area, between population and economy, and between built-up area and economy of 30 cities in Central Plain City Cluster, and divided the coordination into coordinated, relatively coordinated, relatively uncoordinated, and uncoordinated types (Fig. 7).
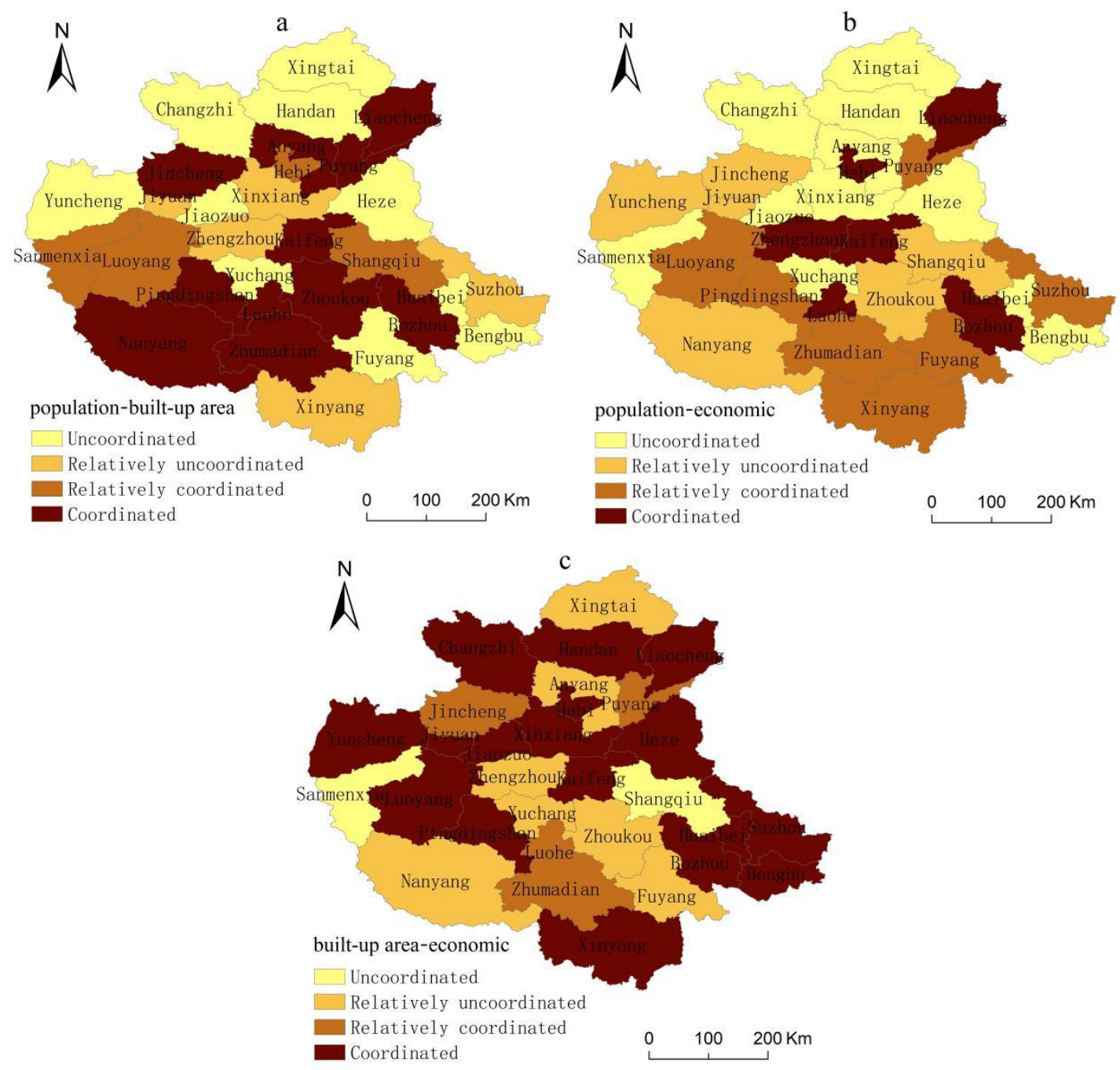

Figure 7. Spatial distribution of population (a), built-up area (b) and economic (c) scale of 30 cities in 2008-2016

(i) In the study period, the coordination relationship between population and built-up area of 30 cities in the Central Plain City Cluster was mainly coordinated and uncoordinated types, accounting for $36.67 \%$ and $33.33 \%$ of the total number of cities, respectively. The coordinated cities were mainly concentrated in the southern and northern parts of the City Cluster, and basically located in the transition area from the core city circle to edge city circle. They not only avoided the flow of urban population to Zhengzhou and outside Henan Province, but also avoided the problem of weak economic development due to geographical location, so the relationship between 
population and built-up area was relatively balanced. Uncoordinated cities were mainly concentrated in the northern part, basically the fringe areas of the City Cluster. These cities received weak radiation of core city circle. Driven by the tide of urbanization, the built-up area expansion in these cities was faster than the population growth. Relatively coordinated and relatively uncoordinated cities were few and mainly distributed along the Longhai (Lianyungang-Lanzhou) Railway, accounting for $13.33 \%$ and $16.67 \%$ of the total number of cities, respectively.

(ii) The coordination relationship between population and economy was mainly uncoordinated type, accounting for $36.67 \%$ of the total number of cities. The number of coordinated, relatively coordinated and relatively uncoordinated cities is roughly equal, $20 \%, 23.33 \%$, and $20 \%$, respectively. Uncoordinated cities were mainly distributed in the northern part of the City Cluster, namely, north of the Yellow River. The expansion of Zhengzhou Metropolitan Zone and construction of all-direction accessible township industrial axis and belt promoted economic development of northern area and also made it absorbed numerous people from other places, so that urban economic growth of northern area was rapid but the population agglomeration was slow. Coordinated cities were scarcely distributed, mainly because these cities had high economic level, were located far from Zhengzhou, and situated in status of local core cities. The relatively coordinated and relatively uncoordinated cities were mainly distributed in the south of the Yellow River. These cities had stable economic development and population growth, and the relationship between economy and population was basically coordinated.

(iii) The coordination relationship between built-up area and economy was mainly coordinated type, accounting for $56.67 \%$ of the total number of cities. Relatively coordinated, relatively uncoordinated, and uncoordinated cities accounted for $13.33 \%$, $23.33 \%$, and $6.67 \%$ of the total number of cities, respectively. Roughly opposite to the coordination relationship between population and economy, the built-up area economy coordinated cities were basically distributed along the Longhai Railway and the north of the Longhai Railway, while the relatively uncoordinated cities were basically distributed in the south of the Longhai Railway.

\section{Logistic growth model}

Urban development has its inherent laws. Predicting the development trend of population, built-up area and economy in the future urban development process has important realistic significance for rationally determining the scale of a city and coordinating the development of urban population, built-up area and economy. On the basis of the data of population, built-up area, and economy during $2008(t=1)$ and 2016 $(t=8)$, According to Equation 6, using the Brute Force search method, we established the Logistic prediction model for urban population, built-up area, and economy of the Central Plain City Cluster:

$$
\begin{aligned}
& P_{t}=\frac{19648.15}{1+8.5822 e^{-0.0217 t}} \\
& A_{t}=\frac{7936.97}{1+3.0806 e^{-0.0695 t}}
\end{aligned}
$$




$$
E_{t}=\frac{74577.44}{1+11.7325 e^{-0.1531 t}}
$$

where $P_{t}$ denotes the population size, $A_{t}$ denotes the built-up area scale, and $E_{t}$ denotes the economic scale. The goodness of fit of the model $R^{2}$ is higher than 0.97 , so the fitting results are very credible. This model can reconstruct the population, built-up area and economic scale of the Central Plain City Cluster in 2008-2016 and predict the value of the following ten years (Chen and Zhang, 2014). As shown in Figure 8, the growth of each variable strictly followed the Logistic growth law, and the reconstruction results were very close to the actual scale of each variable. According to the prediction results, by 2026, the population, built-up area and economic scale of the Central Plain City Cluster were 29.4 million, $4,355 \mathrm{~km}^{2}$, and 4.549 billion yuan, respectively, increasing by 4.75 million, $1,324 \mathrm{~km}$, and 2.777 billion yuan, respectively compared with 2016 . In 2016, the actual per capita built-up area was $123 \mathrm{~m}^{2}$, the per capita GDP was 720,000 yuan, and the average built-up area GDP was 586 million yuan; in 2026, the per capita built-up area was $148 \mathrm{~m}^{2}$, the per capita GDP was 154,700 yuan, and the average builtup area GDP was 1.045 billion yuan. On the whole, in the next decade, the urban population, built-up area and economic scale of the Central Plain City Cluster would show a steady growth trend, among which the economic growth rate will be the fastest, followed by the built-up area growth rate, and the slowest was the population growth rate.

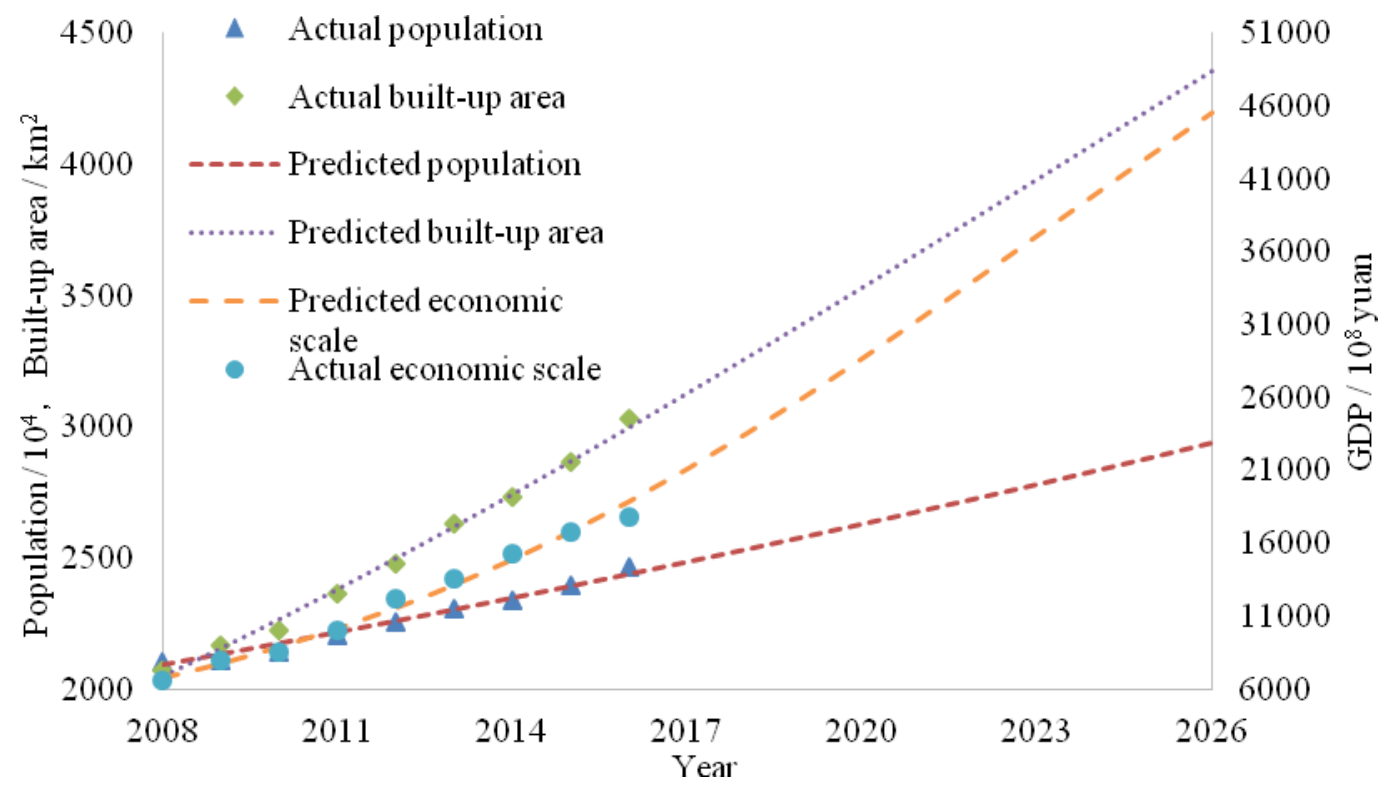

Figure 8. Prediction of urban population, built-up area, and GDP of Central Plain City Cluster (2008-2026)

\section{Discussion}

On the basis of previous studies, we analyzed the spatial and temporal evolution characteristics of the coordination of population - built-up area - economy of the Central Plain City Cluster and came up with some implications and conclusions. The 
urbanization problem of the Central Plain City Cluster is mainly reflected in two aspects. First, the expansion of the urban built-up area leads to occupation of large area of farmland around the city, no guarantee for the life of landless farmers, and imbalance between the population growth, economic growth, and built-up area expansion. These are similar to the situation in other regions of China. Second, compared with the Yangtze River Delta, the Pearl River Delta, and the Beijing-Tianjin-Hebei region, the core cities of the Central Plain City Cluster are less efficient in promoting the surrounding areas. Once there the relationship between the population, built-up area, and economic development of surrounding areas is not coordinated, there will be adverse spatial effect between cities, which will be more unfavorable for the integrated development of the region. Therefore, it is necessary to improve the efficiency of economic growth, reduce the input of such productive resources as land, adjust the industrial structure, increase urban employment, and promote the coordinated and sustainable development of urbanization.

At present, there is still no unified standard for the evaluation system of urbanization coordination measurement. Combining the existing studies, we supplemented the existing theoretical connotation of "urbanization coordination" and stressed that the population - built-up area - economic urbanization subsystems have the same effect on the overall coordinated development. Besides, we built a preliminary framework for analysis of the urbanization coordination, namely, using the proportion of the population, build-up area, and economic growth rate of each city to that of the city cluster to characterize the contribution share of each subsystem; if the contribution share of each subsystem is consistent, it will be deemed to be the theoretical optimal state. The measurement of urban scale is very complicated. In this study, we calculated the future trend of urban population, built-up area and economy from the city cluster level and obtained reasonable results, indicating that our technical ideas are feasible and can be promoted. The calculation results can be used as an important reference for understanding the evolution process and future trend of the relationship between urban population, built-up area, and economy. Considering the complexity of urban scale prediction, especially the imbalance of urbanization development will reduce the accuracy of Logistic prediction, it is necessary to further explore a more comprehensive and effective technical method.

For example, the ecological factor should become an important indicator in the evaluation system of urbanization coordination. Both domestic and foreign theories of sustainable development of cities emphasized three important evaluation indicators "ecology, society, and economy". However, there is still no definite conclusion about how to quantify the weight of each indicator, and this is a difficult but important point of study. Therefore, we attempted to analyze the coordination between population and built-up area, and the conclusion can be used as a reference indicator for the evaluation of human settlement environment. However, we did not explore the coordinated relationship between ecological environment and urbanization. This is a weak point of our study. In the future study, we should analyze the urbanization and the connotation of the ecological environment from the perspective of complexity, and accordingly propose a reasonable analytical framework to explain the coordination mechanism between urbanization and ecological environment from multiple dimensions, so as to make clear the coordinated development relationship between urbanization and ecological environment, and ultimately promote the sustainable urban development. 


\section{Conclusions}

Taking the Central Plain City Cluster as the research object, and using the center-ofgravity coupling model, unbalance index, and coordination measure model, this paper analyzed spatial and temporal evolution characteristics of coordination between urban population, built-up area, and economy in 2008-2016, and predicted their overall development trend according to the Logistic model. The results shown are as follows:

(i) The growth rate of urban population, built-up area and economy of Central Plain City Cluster shows a fluctuating trend. The economic growth is faster than that of population and built-up area. The variation trend of growth rate of built-up area expansion and population is basically consistent, while the growth rate of economy shows a significant decline, and the stage characteristics and spatial differences of their evolution are significant.

(ii) From the macro perspective, the shift direction of population is opposite to that of built-up area and economic gravity, the coordination between population and built-up area and economy gradually declines, while the shift direction of built-up area is the same as that of the economic center-of-gravity, and the coordination between built-up area and economy is gradually strengthened. The unbalance index of population, builtup area and economy is on the rise, while unbalance index of population and built-up area remains stable.

(iii) The coordination between population and built-up area and between population and economy is poor, with the population - built-up area and population -economy coordinated cities accounting for $36.67 \%$ and $20 \%$ of the total number of cities. The coordination between built-up area and economy is good, with built-up area - economy coordinated cities accounting for $56.67 \%$ of the total number of cities. The coordination between these three items presents significant spatial difference characteristics.

(iv) According to the prediction, the growth of each variable strictly follows the Logistic growth law, and the reconstruction results are very close to the actual scale of each variable. According the prediction, the overall size of urban population, built-up area and economy will be 29.4 million, $4,355 \mathrm{~km} 2$, and 4.549 billion yuan in 2026, and such prediction is very credible.

Acknowledgements. Great gratitude to the fund support of the National Natural Science Foundation of China (41771565), Henan provincial government decision research tendering project (2017B189).

\section{REFERENCES}

[1] Ameen, R. F. M., Mourshed, M., Li, H. (2015): A critical review of environmental assessment tools for sustainable urban design. - Environmental Impact Assessment Review 55: 110-125.

[2] Chan, R. C. K., Yao, S. M. (1999): Urbanization and sustainable metropolitan development in China: Patterns, problems and prospects. - GeoJournal 3: 269-277.

[3] Chen, C. (2008): Research on healthy development of urbanization. - Territory \& Natural Resources Study 30(4): $7-9$.

[4] Chen, Y. G., Zhang, L. (2014): An allometric analysis of the scaling relations between population and urban area of Xinyang. - Progress in geography 33(8): 1058-1067.

[5] Cohen, B. (2008): Urbanization in developing countries: current trends, future projections, and key challenges for sustainability. - Technology in Society 28(1): 63-80. 
[6] Di, Q. B., Han, S. S., Han, Z. L. (2016): Spatial pattern of economic carrying capacity of cities at prefecture level and above in China. - Geographical Research 35(2): 337-352.

[7] Fan, H., Liu, W. D., Wu, Z. B., Zhang, H. Y. (2014): The coupling coordination evaluation between population urbanization and land urbanization in Zhejiang Province. Economic Geography 34(12): 21-28.

[8] Feng, Z. M., Yang, Y. Z., You, Z., Zhang, J. H. (2014): Research on the suitability of population distribution at the county level in China. - Acta Geographica Sinica 69(6): 723-737.

[9] Friedmann, J. (2010): Four theses in the study of China's urbanization. - International Journal of Urban \& Regional Research 30(2): 440-451.

[10] He, S. W., Shao, X. (2018): Spatial clustering and coupling coordination of populationland-economic urbanization in Beijing-Tianjin-Hebei region. - Economic Geography 38(1): 95-102.

[11] Henderson, V. (2002): Urbanization in developing countries. - New Zealand Geographer 17(1): 89-112.

[12] Holden, S. T., Otsuka, K. (2014): The roles of land tenure reforms and land markets in the context of population growth and land use intensification in Africa. - Food Policy 48: 88-97.

[13] Li, J. F., Yu, H. F., Fu, Y. C., Zhao, Y. L. (2018): Spatial-temporal changes of population-economy-land-society-ecology coordination level of urbanization and clustering: A case of Guangdong Province, China. - Progress in Geography 37(2): 287298.

[14] Li, X. S., Zhang, S. L., Wang, Y. H. (2011): Quantitative study of construction land increase limit year in the economic transition stage in China. - Journal of Natural Resources 726(7): 1058-1059.

[15] Lin, G. C. S. (2006): Peri-urbanism in globalizing China: a study of new urbanism in Dongguan. - Eurasian Geography \& Economics 47(1): 28-53.

[16] Lin, G. C. S. (2007): Chinese Urbanism in Question: State, Society, and the Reproduction of Urban Spaces. - Urban Geography 28(1): 7-29.

[17] Liu, A. M., Yang, D. C. (2011): City scale, resource allocation and economic growth. Modern Economic Science 33(1): 106-113, 128.

[18] Liu, F. W., Xu, H. Z., Wang, S. (2014): Analysis on spatial-temporal coupling coordinate degree among population, land and economy urbanization: based on China provincial panel data. - Urban Development Studies 21(8): 7-11.

[19] Liu, Y., Yamauchi, F. (2013): Population density, migration, and the returns to human capital and land: Insights from Indonesia. - IFPRI Discussion Papers 48(1): 182-193.

[20] Liu, Y. G., Wang, F. L. (2011): Holistic forecast method of land use in leap-forward of urbanization. - Geographical Research 30(7): 1187-1197.

[21] Murakami, A., Zain, A. M., Takeuchi, K., Tsunekawa, A., Yokota, S. (2005): Trends in urbanization and patterns of land use in the Asian mega cities Jakarta, Bangkok, and Metro Manila. - Landscape \& Urban Planning 70(3): 251-259.

[22] Niu, S. W., Lan, Z. C., Hu, Y. Y. (2014): Urbanization: population growth constraint and policy implication. - China Population, Resources and Environment 24(8): 49-56.

[23] Ravallion, M., Chen, S., Sangraula, P. (2007): New evidence on the urbanization of global poverty. - Population and Development Review 33: 667-701.

[24] Shi, Y. S. (2015): Dialectical examination of the relationship between land urbanization and population urbanization. - Shanghai Land \& Resources 36(2): 9-13.

[25] Tang, Y. H. (2013): Research on the concept of urbanization and new definition. Academic Forum 5: 113-116.

[26] Wang, C. X., Wang, B. T., Wang, X. Y. (2016): Study on population urbanization and land urbanization allometric growth in China based on the structure. - China Population, Resources and Environment 8(26): 135-141. 
[27] Wang, F., Zhang, F., Lin, X. Y., Shi, T. W., Chen, H. T. (2018): Study on coupling coordination degree among "population, land, economy and society" urbanization in the Yangtze River Delta Region. - Journal of Industrial Technological Economics 4: 45-52.

[28] Wang, J., Fang, C. L., Li, Y. R. (2014): Spatio-temporal analysis of population and construction land change in urban and rural China. - Journal of Natural Resources 29(8): 1271-1281.

[29] Xu, Y. X., Chen, F., Pu, L. J. (2007): A retrospect and prospect on research of urban spatial and land use expansion. - Economic Geography 27(2): 296-301.

[30] Yang, Y. Z., Feng, Z. M., Zhao, Y. D., You, Z. (2013): Coordination between urban land expansion and population growth in China. - Geographical Research 32(9): 1168-1678.

[31] You, Z., Lei, Y. L., Feng, Z. M., Yang, Y. Z. (2017): Comparative study on the social and economic coordination of the population distribution and regional differences of BeijingTianjin-Hebei, Yangtze River Delta and Pearl River Delta city clusters. - Modern Urban Research 3: 78-84.

[32] Zhang, L. Q., Chen, S. P., Chen, B. P. (2014): The contribution of land to the economic growth and inflection point of its logistic curve in Anhui Province in recent 15 years. Scientia Geographica Sinica 34(1): 40-46.

[33] Zhou, Y., Huang, X. J., Xu, G. L., Li, J. B. (2016): The coupling and driving forces between urban land expansion and population growth in Yangtze River Delta. Geographical Research 35(2): 313-324. 